\title{
ENHANCEMENT OF SOLUBILITY AND DISSOLUTION OF IBUPROFEN BY SOLID DISPERSION TECHNIQUE AND FORMULATION OF SUSTAINED RELEASE TABLETS CONTAINING THE OPTIMISED BATCH OF SOLID DISPERSION
}

\author{
ABHIK KAR*, ABDUL BAQUEE AHMED \\ Girijananda Chowdhury Institute of Pharmaceutical Science, Azara, Guwahati 781017, Assam \\ Email: abhik666.ak@gmail.com
}

Received: 23 May 2017, Revised and Accepted: 22 Jul 2017

\begin{abstract}
Objective: The present study was aimed to enhance the solubility of poorly water soluble drug Ibuprofen using solid dispersion technique and to develop sustained release tablets containing solid dispersion granules of the optimized batch. Ibuprofen is a non-steroidal anti-inflammatory drug (NSAID) with analgesic, antipyretic, and anti-inflammatory properties

Methods: Solid dispersions of Ibuprofen were prepared by using PEG 20000 and Poloxamer 407 in different weight ratios by fusion and solvent evaporation method. Drug-carrier physical mixtures were also prepared. Solid dispersions were characterized by saturation solubility, drug content, in vitro dissolution, FTIR and DSC analysis. Solid dispersion formulation, SDF9 (PEG 20000 and Poloxamer 407, 1:3:3) prepared by solvent evaporation method was considered as the optimized batch. Sustained release tablets containing the solid dispersion granules of the optimized batch were prepared by direct compression method using HPMC K100M at three concentrations (10\%, 14\%, 18\% w/w). The prepared formulations were evaluated for hardness, thickness, weight variation, friability, in vitro dissolution studies and release kinetics modelling.
\end{abstract}

Results: Solid dispersion formulation, SDF9showed 95.09\% drug release in 60 min and considered as the optimized batch. Tablet formulation, FT3 (HPMC K100M 18\% w/w) showed 96\% drug release for $12 \mathrm{~h}$.

Conclusion: Solid dispersions of ibuprofen using a combination of PEG 20000 and poloxamer 407 by solvent evaporation method may result in higher aqueous solubility of the drug. Also sustained release tablets containing solid dispersion granules of ibuprofen, using HPMC K100M may be a promising approach to extend the release rate of the drug from the solid dispersion for $12 \mathrm{~h}$.

Keywords: Solid dispersion, Ibuprofen, PEG, Poloxamer, Sustained Release, HPMC K100M

(C) 2017 The Authors. Published by Innovare Academic Sciences Pvt Ltd. This is an open access article under the CC BY license (http://creativecommons.org/licenses/by/4.0/) DOI: http://dx.doi.org/10.22159/ijcpr.2017v9i5.22134

\section{INTRODUCTION}

The poor aqueous solubility and dissolution rate of a drug is one of the biggest challenges in pharmaceutical development. Especially the compounds belonging to BCS Class II, which are poorly soluble and highly permeable, tend to present solubility or dissolution ratelimited absorption. Despite their high permeability, these drugs often have low oral bioavailability because of their slow and limited release of drug in gastrointestinal fluid [1]

One of the most successful strategies to improve the dissolution of poorly soluble drugs is solid dispersion technique. The term solid dispersions have been defined as a dispersion of a drug in an inert carrier or matrix at the solid state prepared by solvent, melting or solvent-melting method. Numerous studies on solid dispersions have been published and have showed many advantageous properties of solid dispersions in improving the solubility and dissolution rate of poorly water soluble drugs. These advantages include reducing particle size, possibly to the molecular level, enhancing wet ability and porosity, as well as changing drug crystalline state, preferably into the amorphous state [4].

Oral route is the most oldest and convenient route for the administration of drugs because of low cost of therapy and higher patient compliance. During the past three decades, numerous oral drug delivery systems have been developed from which the drug can be released over a defined period of time at a predetermined and controlled rate. The sustained release, controlled release, extended release, timed release etc. are terms used to identify drug delivery system that are designed to achieve a prolonged therapeutic effect by continuously releasing medication over an extended period of time after administration of a single dose [7]. The oral sustained release formulation has been developed for those drugs that are easily absorbed from the gastrointestinal tract (GIT) and have a short half-life, which are eliminated quickly from the blood circulation. They release the drug slowly into the GIT and maintain a constant drug concentration in the plasma within the therapeutic range for a longer period of time. Sustained release dosage forms provide advantages like reduction of dosing frequency, less local and systemic side effects and greater patient compliance [8].

Ibuprofen, a propionic acid derivative, is a non-steroidal antiinflammatory drug (NSAID) with analgesic, antipyretic and antiinflammatory properties. Its pharmacological effects are due to inhibition of COX-2which decreases the synthesis of prostaglandins involved in mediating inflammation, pain, fever and swelling. Antipyretic effects may be due to action on the hypothalamus, resulting in an increased peripheral blood flow, vasodilation and subsequent heat dissipation. Inhibition of COX-1 is thought to cause some of the side effects of ibuprofen including GI ulceration. Ibuprofen is a BCS class II drug and thus possesses dissolution ratelimited absorption which leads to low oral bioavailability. It has a biological half-life of 1.3-3 h. [5]

The aim of the present study was to enhance the aqueous solubility and dissolution of ibuprofen by solid dispersion technique using selected hydrophilic polymers like PEG 20000 and poloxamer 407. Also to fabricate sustained release tablets containing solid dispersion granules of the optimised batch, using HPMC K100M to extend the release rate of the drug from the solid dispersion for $12 \mathrm{~h}$.

\section{MATERIALS AND METHODS}

\section{Materials}

Ibuprofen was obtained from Yarrow Chem, Mumbai-37, India. Methanol and ethanol were obtained from Changshu Yangyuan 
Chemical Co., Ltd., Sozhou, China. Hydrochloric acid, potassium dihydrogen phosphate, sodium hydroxide, PEG 20000, Poloxamer 407,HPMC K100M,Aerosil@200 were obtained from Merc Specialist Pvt. Ltd., Shiv sagar estate, Mumbai-400018, India. Spray dried lactose and talc were obtained from Balaji Drugs, Mumbai-37, India. All chemicals used were of analytical grade.

\section{Methods}

\section{Preparation of solid dispersions}

\section{Melting or fusion method [2]}

The prerequisite for this technique is crystalline starting materials. Solid dispersions of Ibuprofen were prepared by melting or fusion method using PEG 20000 and Poloxamer 407 as hydrophilic carriers respectively at weight ratios of 1:1, 1:2 and 1:3 (drug: carrier). The required amount of drug and carrier were melted in a petri-dish on a hot plate maintained at $80{ }^{\circ} \mathrm{C}$. The molten mass was then mixed thoroughly with a glass rod for homogeneous mixing. Then the mass was cooled at room temperature, powdered in a mortar, sieved through a 60 -mesh screen and stored in a desiccator for further evaluation.

\section{Solvent evaporation method [4]}

An important prerequisite for the manufacture of solid dispersion using this method is that both the drug and the carrier should be soluble in the solvent. Solid dispersions of Ibuprofen were prepared by solvent evaporation method using a combination of PEG 20000 and Poloxamer 407 at weight ratios of 1:1:1, 1:2:2 and 1:3:3 (drug: carrier: carrier). The respective amount of PEG 20000 and poloxamer 407 were dissolved in sufficient quantity of methanol in a petri dish and then the required amount of drug was added slowly with continuous stirring to obtain a clear solution. The solution was then heated on a water bath until the solvent is evaporated. The resultant solid dispersions were allowed to dry at room temperature powdered in a mortar, sieved through a 60-mesh screen and stored in a desiccator for further evaluation.

Table 1: Formulation of solid dispersions by melting/fusion method

\begin{tabular}{|c|c|c|c|c|c|c|}
\hline Ingredients & SDF1 & SDF2 & SDF3 & SDF4 & SDF5 & SDF6 \\
\hline Ibuprofen(mg) & 500 & 500 & 500 & 500 & 500 & 500 \\
\hline PEG $20000(\mathrm{mg})$ & 500 & 1000 & 1500 & & & \\
\hline Poloxamer 407(mg) & & & & 500 & 1000 & 1500 \\
\hline
\end{tabular}

Table 2: Formulation of solid dispersions by solvent evaporation method

\begin{tabular}{|c|c|c|c|}
\hline Ingredients & SDF7 & SDF8 & SDF9 \\
\hline Ibuprofen(mg) & 500 & 500 & 500 \\
\hline PEG $20000(\mathrm{mg})$ & 500 & 1000 & 1500 \\
\hline Poloxamer 407(mg) & 500 & 1000 & 1500 \\
\hline
\end{tabular}

\section{Preparation of physical mixture [3]}

The physical mixtures in the same weight ratio as the solid dispersions mentioned above were prepared by thoroughly mixing the appropriate amounts of ibuprofen and carrier(s) for $10 \mathrm{~min}$ in a mortar. The mixtures were sieved through a 60 -mesh screen and stored in a desiccator for further evaluation.

Table 3: Formulation of physical mixtures

\begin{tabular}{llll}
\hline Formulation & Ibuprofen (mg) & PEG 20000 (mg) & Poloxamer407(mg) \\
\hline PMF1 & 500 & 500 & \\
PMF2 & 500 & 1000 & 1500 \\
PMF3 & 500 & & 500 \\
PMF4 & 500 & & 1000 \\
PMF5 & 500 & 500 & 1500 \\
PMF6 & 500 & 1000 & 500 \\
PMF7 & 500 & 1500 & 1000 \\
PMF8 & 500 & & 1500 \\
PMF9 & 500 & & \\
\hline
\end{tabular}

\section{Evaluation of solid dispersions}

\section{Drug content [3]}

An amount equivalent to $25 \mathrm{mg}$ of ibuprofen from each formulation was taken and dissolved in $50 \mathrm{ml}$ of methanol in stoppered conical flasks. The sealed flasks were agitated on a rotary shaker for $1 \mathrm{~h}$. The solutions were filtered and diluted suitably with methanol and assayed using a UV-VIS Spectrophotometer for drug content at 221 nm.

Percent drug content= (practical drug content in solid dispersions $/$ theoretical drug content in solid dispersions) x 100

\section{Saturation solubility determination [3]}

The saturation solubility of the formulations was determined in distilled water, $0.1 \mathrm{~N} \mathrm{HCl}$ and phosphate buffer $\mathrm{pH} 6.8$ by the following procedure: the Excess amount of each formulation was taken and dissolved in a measured amount of solution of each solvent in a volumetric flask to get a saturated solution. Each solution was shaken in a rotary shaker for a period of $24 \mathrm{~h}$. After $24 \mathrm{hs}$ the solutions were filtered and diluted suitably. The concentration of ibuprofen in each solution was analysed by UV-VIS spectrophotometer using distilled water, $0.1 \mathrm{~N} \mathrm{HCl}$ and phosphate buffer $\mathrm{pH} 6.8$ as blank respectively.

\section{In vitro dissolution studies [6]}

Powder dissolutions were performed using USP Type-II dissolution apparatus, thermostatically controlled at $37^{\circ} \mathrm{C} \pm 0.5^{\circ} \mathrm{C}$ and phosphate buffer pH 6.8 was used as dissolution media. Samples of drug, solid dispersions and physical mixtures equivalent to $100 \mathrm{mg}$ of ibuprofen were introduced into the $900 \mathrm{ml}$ of dissolution medium, stirred at $50 \mathrm{rpm}$. Samples were withdrawn at 15, 30, 45, and $60 \mathrm{~min}$ The volume withdrawn at each time interval was replaced with a fresh quantity of the dissolution medium. The samples were filtered diluted accordingly and analysed spectrophotometrically in UV-VIS Spectrophotometer. 


\section{Fourier transform infrared spectroscopy study [3]}

The FT-IR study was performed for the drug ibuprofen, PEG 20000, poloxamer 407 and selected solid dispersion formulations-SDF7, SDF8, SDF9. Another FT-IR study was performed for the physical mixture of SDF9 and HPMC K100M to assess the drug-excipient compatibility before the formulation of sustained release tablets. A small amount of each sample was taken in a mortar and triturated. The triturated sample was taken in the sample chamber of the instrument and scanned from $400 \mathrm{~cm}-1$ to $4000 \mathrm{~cm}-1$ in Bruker FTIR spectrophotometer. The spectra obtained were compared and interpreted for the functional group peaks.

\section{Differential scanning calorimetry study [6]}

Differential scanning calorimetry (DSC) of the drug and a selected formulation SDF9 were performed using Perkin Elmer DSC 4000 for the measurement of heat loss or gain resulting from physical or chemical changes within a sample as a function of temperature. About 6-7 mg of the sample was weighed in aluminium DSC pans and hermetically sealed capsules were prepared with aluminium lids. An initial ramp was used to jump the temperature to $30^{\circ} \mathrm{C}$ and then a constant heating rate of $10{ }^{\circ} \mathrm{C} / \mathrm{min}$ was used up to $400{ }^{\circ} \mathrm{C}$ under nitrogen atmosphere.

\section{Preparation of sustained release tablets containing solid dispersion granules}

Solid dispersion formulation SDF9 was chosen the optimised formulation based on the dissolution characteristics and sustained release tablets containing the solid dispersion granules of the optimised batch was prepared. Sustained release tablets containing the solid dispersion granules equivalent to $100 \mathrm{mg}$ of ibuprofen were prepared by direct compression method using HPMC K100M as release retarding polymer at three different concentrations $(10 \%, 14 \%$ and $18 \% \mathrm{w} / \mathrm{w})$. Spray dried lactose was used as directly compressible diluent. Other excipients were Aerosil ${ }^{\circledR} 200$ (colloidal silicon dioxide) as a Glidant and Talc as a lubricant. The solid dispersion granules and all other excipients were weighed accurately and individually passed through sieve number 60 and mixed thoroughly by triturating up to $15 \mathrm{~min}$. The powder mixture was compressed using $12 \mathrm{~mm}$ diameter, flat punches in a single punch tablet compression machine [8].

Table 4: Formulation of sustained release tablets containing solid dispersion granules

\begin{tabular}{|c|c|c|c|}
\hline Ingredients & FT1 & FT2 & FT3 \\
\hline Solid dispersion(Equivalent to $100 \mathrm{mg}$ Ibuprofen) & $416 \mathrm{mg}$ & $416 \mathrm{mg}$ & $416 \mathrm{mg}$ \\
\hline Spray Dried Lactose & $110 \mathrm{mg}$ & $86 \mathrm{mg}$ & $62 \mathrm{mg}$ \\
\hline HPMC K100M & $60 \mathrm{mg}(10 \%)$ & $84 \mathrm{mg}(14 \%)$ & $108 \mathrm{mg}(18 \%)$ \\
\hline Aerosil@ 200 & $5 \mathrm{mg}$ & $5 \mathrm{mg}$ & $5 \mathrm{mg}$ \\
\hline Talc & $9 \mathrm{mg}$ & $9 \mathrm{mg}$ & $9 \mathrm{mg}$ \\
\hline Total & $600 \mathrm{mg}$ & $600 \mathrm{mg}$ & $600 \mathrm{mg}$ \\
\hline
\end{tabular}

\section{Evaluation of post-compression parameters of sustained release tablets}

\section{Weight variation [7]}

20 tablets were selected from each batch, weighed individually and the average weight was calculated. The individual weight of the tablets was then compared to the average weight. The percentage of weight variation was calculated using the following formula-

$\%$ weight variation $=($ Individual Weight-Average Weight $) /($ Average Weight) $\times 100$

\section{Thickness [7]}

Thickness of 10 randomly selected tablets from each formulation was examined by using Vernier callipers.

\section{Hardness [9]}

The hardness of the tablets was determined using Monsanto hardness tester. It was expressed in $\mathrm{kg} / \mathrm{cm}^{2} .3$ tablets were randomly picked from each batch and analysed for hardness.

\section{Friability [8]}

10 tablets of each batch were weighed and put into Roche friabilator and operated for $4 \mathrm{~min}$ at $25 \mathrm{rpm}$. The tablets were recovered and freed from dust and weighed. Friability was calculated from the following formula:

$$
\% \text { Friability }=\frac{\text { Initial weight }- \text { Final weight }}{\text { Initial weight }} \times 100
$$

\section{Drug content [9]}

3 tablets from each batch were weighed and powdered. Powder equivalent to $100 \mathrm{mg}$ of drug was weighed and dissolved in $100 \mathrm{ml}$ of phosphate buffer $\mathrm{pH} 6.8$, filtered, diluted suitably and analysed for drug content at $221 \mathrm{~nm}$ using UV-VIS spectrophotometer.

\section{In vitro dissolution studies [8]}

The release rate of all designed formulations was studied up to $12 \mathrm{~h}$. The procedure was determined using USP Type II dissolution test apparatus. The dissolution test was performed using $900 \mathrm{ml}$ of Phosphate Buffer of $\mathrm{pH} 6.8$ at $37 \pm 0.5^{\circ} \mathrm{C}$ and $50 \mathrm{rpm}$. A sample of 10 $\mathrm{ml}$ of the solution was withdrawn from the dissolution apparatus at $1 \mathrm{~h}$ intervals with the replacement of fresh dissolution medium for $12 \mathrm{~h}$. The samples were filtered and diluted to a suitable concentration with phosphate buffer. The absorbance of these solutions was measured at $221 \mathrm{~nm}$ using a Shimadzu UV-1800 double-beam spectrophotometer.

\section{Kinetics and mechanism of release analysis [8]}

To study the release kinetics, the data obtained from in vitro drug release studies were plotted in various kinetic models like zero order, first order, Higuchi's model, Korsmeyer-Peppas power law equation and Hixson-Crowell cube root equation.

\section{RESULTS}

Table 5: \% Drug content of solid dispersions and physical mixtures

\begin{tabular}{ll}
\hline Formulation & \% drug content \\
\hline PM1 & 98.45 \\
PM2 & 98.02 \\
PM3 & 98.78 \\
SDF1 & 97.65 \\
SDF2 & 97.23 \\
SDF3 & 98.65 \\
PM4 & 98.74 \\
PM5 & 98.50 \\
PM6 & 98.63 \\
SDF4 & 98.23 \\
SDF5 & 98.25 \\
SDF6 & 98.45 \\
PM7 & 98.65 \\
PM8 & 98.21 \\
PM9 & 98.36 \\
SDF7 & 97.65 \\
SDF8 & 96.36 \\
SDF9 & 98.87 \\
\hline
\end{tabular}


Table 6: Saturation solubility of solid dispersions and physical mixtures

\begin{tabular}{|c|c|c|c|}
\hline Formulation & Distilled water $(\mathrm{mg} / \mathrm{ml})$ & Phosphate buffer pH $6.8(\mathrm{mg} / \mathrm{ml})$ & $0.1 \mathrm{~N} \mathrm{HCl}(\mathrm{mg} / \mathrm{ml})$ \\
\hline PM1 & $0.122 \pm 0.05$ & $0.465 \pm 0.06$ & $0.187 \pm 0.14$ \\
\hline PM2 & $0.150 \pm 0.06$ & $0.529 \pm 0.09$ & $0.201 \pm 0.07$ \\
\hline PM3 & $0.154 \pm 0.05$ & $0.641 \pm 0.19$ & $0.205 \pm 0.05$ \\
\hline SDF1 & $0.223 \pm 0.09$ & $0.552 \pm 0.05$ & $0.223 \pm 0.09$ \\
\hline SDF2 & $0.284 \pm 0.06$ & $0.767 \pm 0.03$ & $0.245 \pm 0.06$ \\
\hline SDF3 & $0.456 \pm 0.05$ & $0.924 \pm 0.09$ & $0.263 \pm 0.09$ \\
\hline PM4 & $0.254 \pm 0.09$ & $0.487 \pm 0.15$ & $0.230 \pm 0.06$ \\
\hline PM5 & $0.326 \pm 0.11$ & $0.502 \pm 0.09$ & $0.245 \pm 0.08$ \\
\hline PM6 & $0.354 \pm 0.07$ & $0.574 \pm 0.05$ & $0.260 \pm 0.14$ \\
\hline SDF4 & $0.369 \pm 0.06$ & $0.560 \pm 0.14$ & $0.356 \pm 0.09$ \\
\hline SDF5 & $0.451 \pm 0.14$ & $0.841 \pm 0.05$ & $0.398 \pm 0.19$ \\
\hline SDF6 & $0.545 \pm 0.06$ & $1.002 \pm 0.11$ & $0.402 \pm 0.05$ \\
\hline PM7 & $0.288 \pm 0.05$ & $0.767 \pm 0.06$ & $0.304 \pm 0.09$ \\
\hline PM8 & $0.365 \pm 0.06$ & $0.784 \pm 0.08$ & $0.365 \pm 0.09$ \\
\hline PM9 & $0.463 \pm 0.06$ & $0.965 \pm 0.04$ & $0.398 \pm 0.05$ \\
\hline SDF7 & $0.596 \pm 0.12$ & $1.008 \pm 0.17$ & $0.589 \pm 0.06$ \\
\hline SDF8 & $0.742 \pm 0.05$ & $1.103 \pm 0.09$ & $0.841 \pm 0.07$ \\
\hline SDF9 & $1.009 \pm 0.09$ & $1.589 \pm 0.11$ & $1.203 \pm 0.12$ \\
\hline
\end{tabular}

In vitro dissolution study of solid dispersions

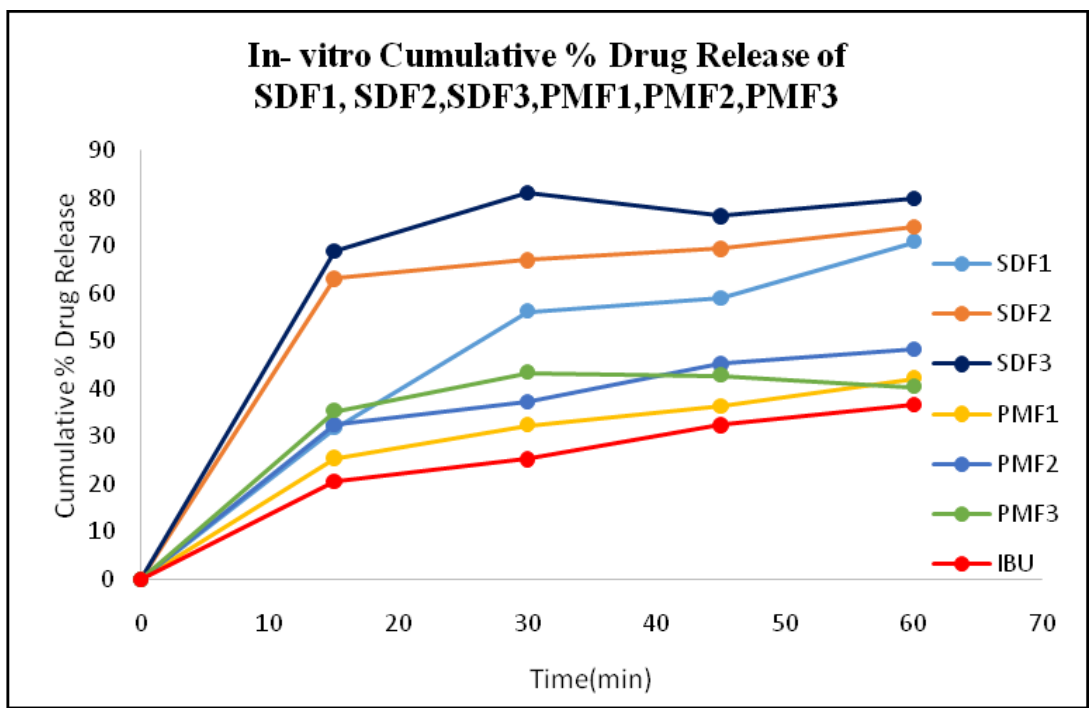

Fig. 1: In vitro cumulative \% drug release of solid dispersions using PEG 20000

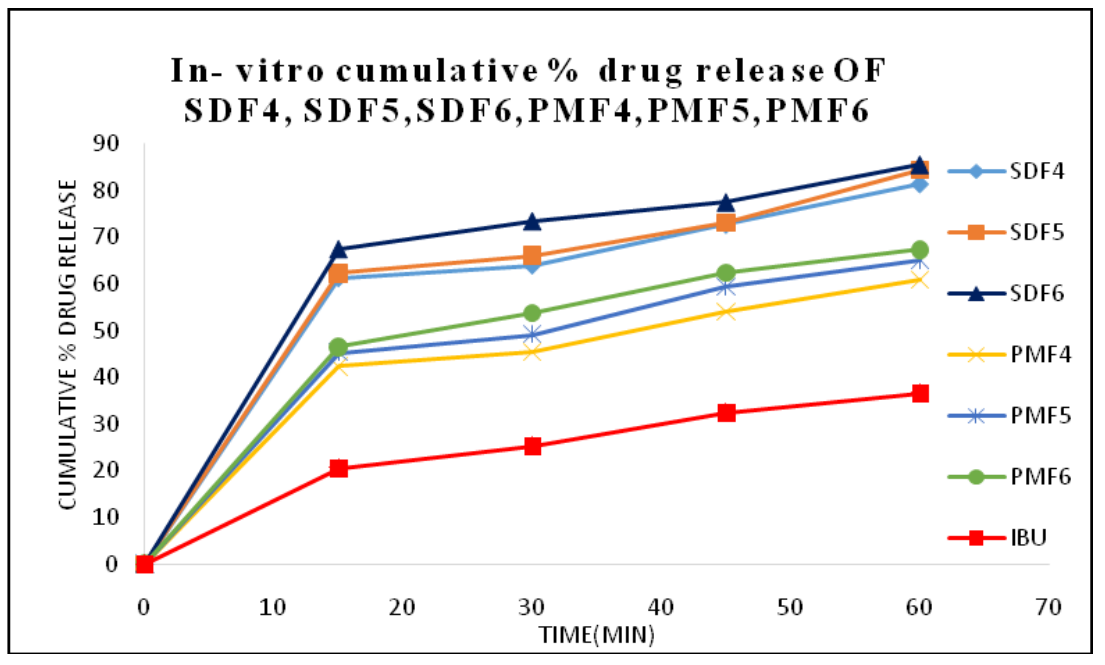

Fig. 2: In vitro cumulative \% drug release of solid dispersions using poloxamer407 


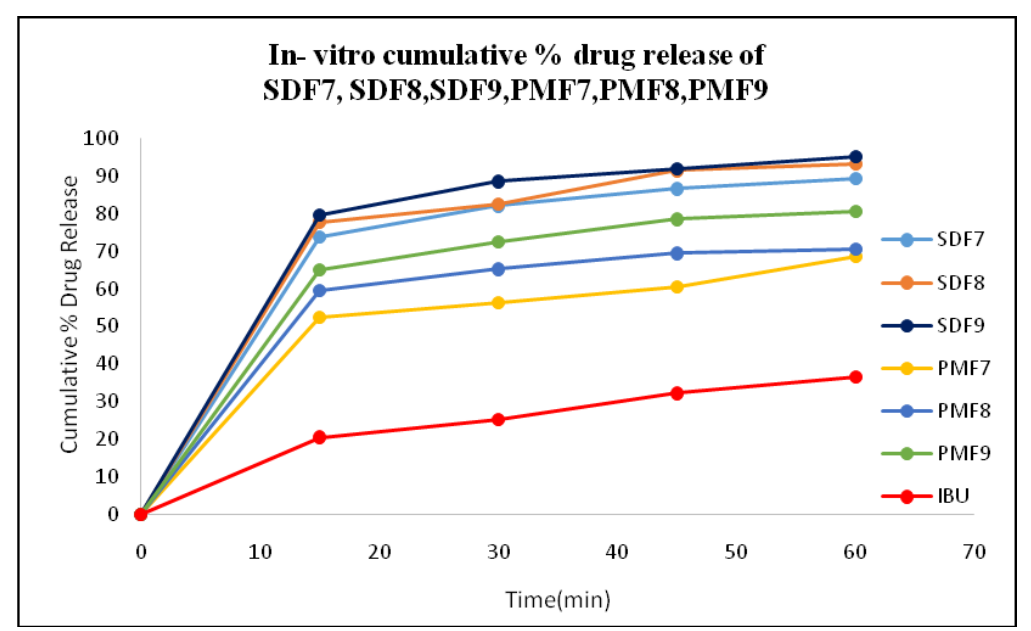

Fig. 3: In vitro cumulative \% drug release of solid dispersions using combination of PEG 20000 and poloxamer 407

FT-IR study

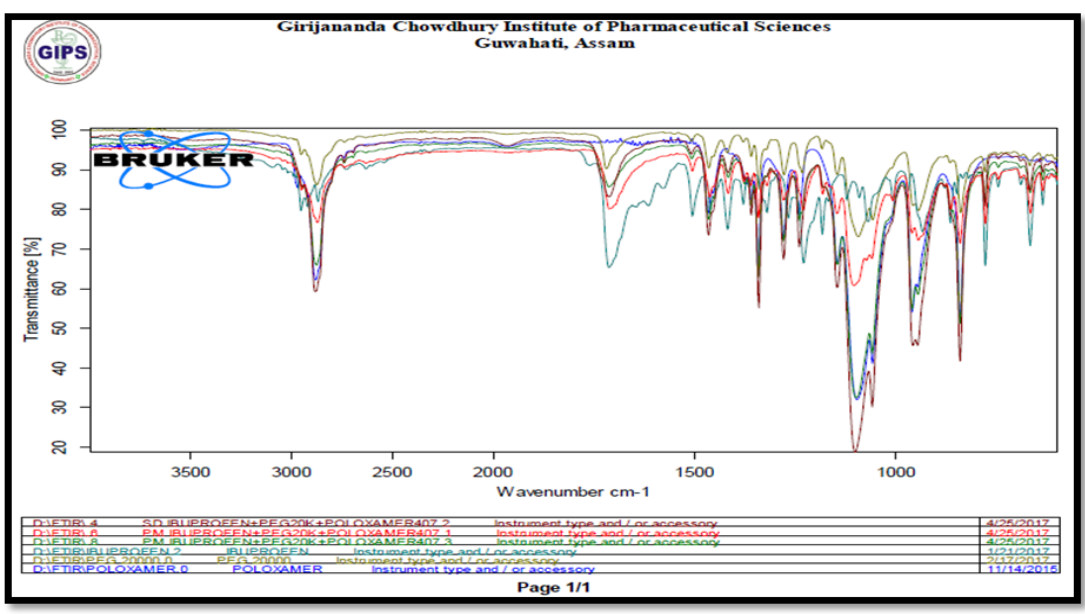

Fig. 4: IR spectra of ibuprofen, PEG 20000, poloxamer 407 and solid dispersions SDF7, SDF8, SDF9

Table 7: IR spectra interpretation of drug ibuprofen

\begin{tabular}{lll}
\hline S. No. & Interpretation & IR absorption bands(cm $\mathbf{- 1})$ \\
\hline 1 & $\mathrm{C}-\mathrm{H}$ & 2953.83 \\
2 & $\mathrm{C}-\mathrm{C}$ & 1069.13 \\
3 & $\mathrm{C}=\mathrm{O}$ & 1712.94 \\
4 & $\mathrm{C}=\mathrm{C}$ & 1717.94 \\
5 & $\mathrm{O}-\mathrm{H}$ & 3088.96 \\
\hline
\end{tabular}

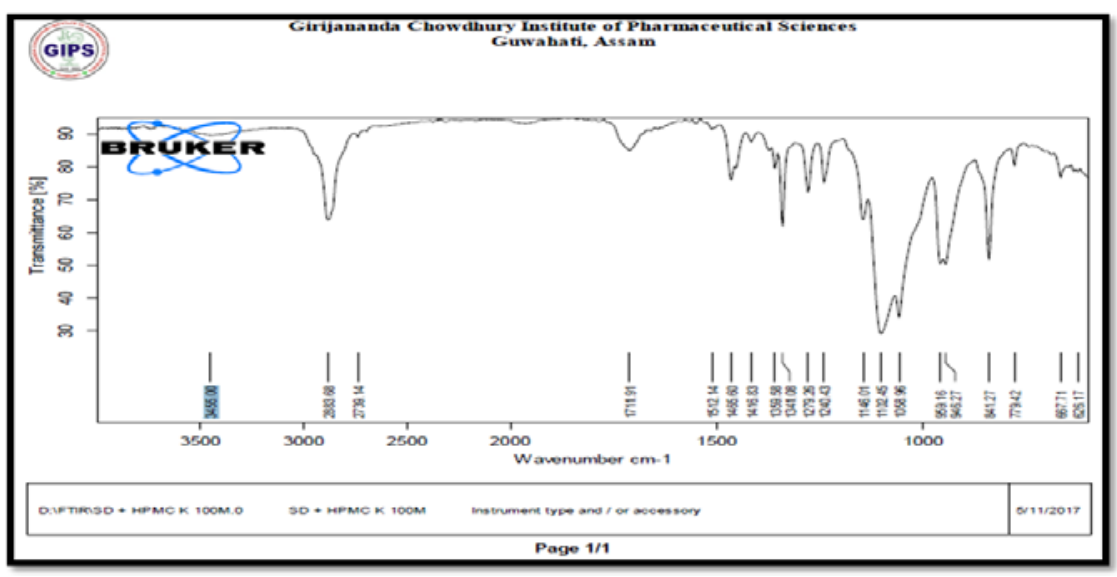

Fig. 5: IR spectra of SDF9 and HPMC K100M 
Differential scanning calorimetry (DSC) analysis

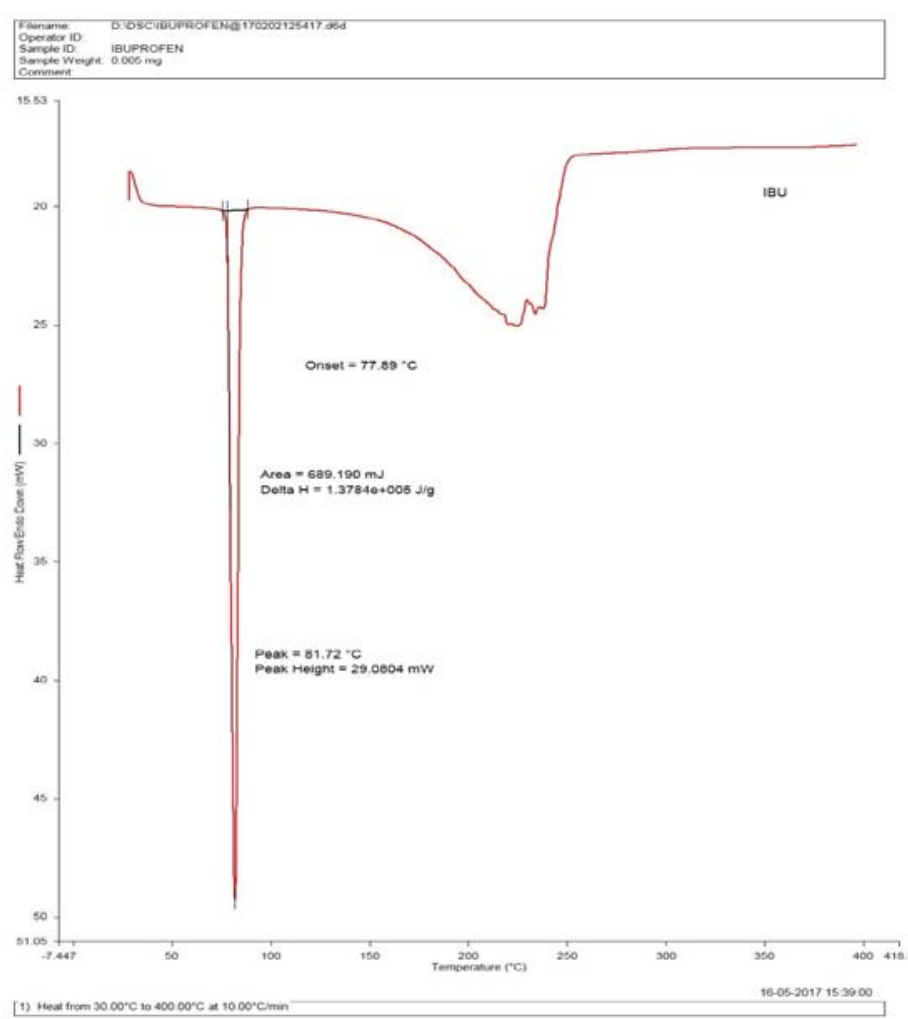

Fig. 6: DSC of ibuprofen

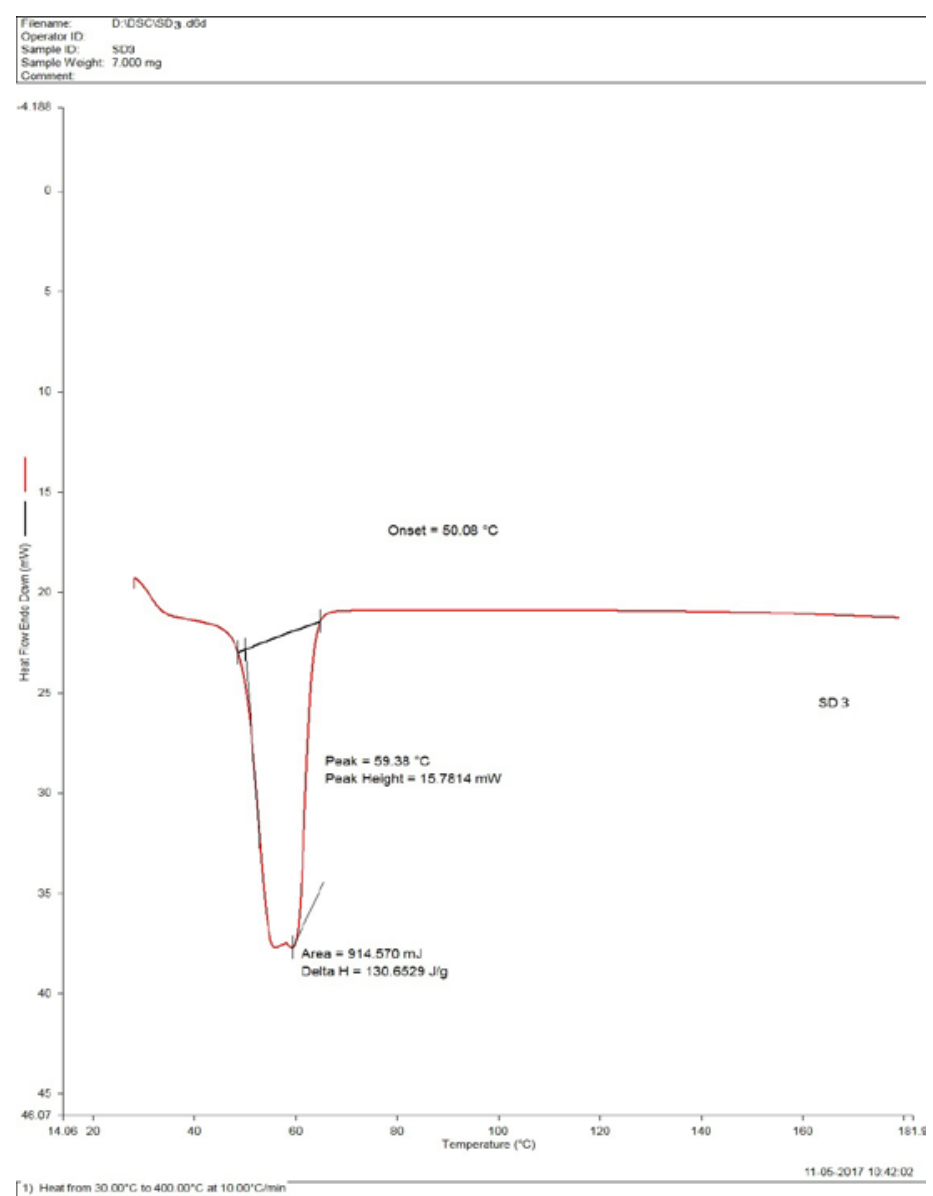

Fig. 7: DSC of IBU+PEG 20000+POLO 407 solid dispersion (1:3:3) [SDF9] 
Table 8: Evaluation of post compression parameters of tablet

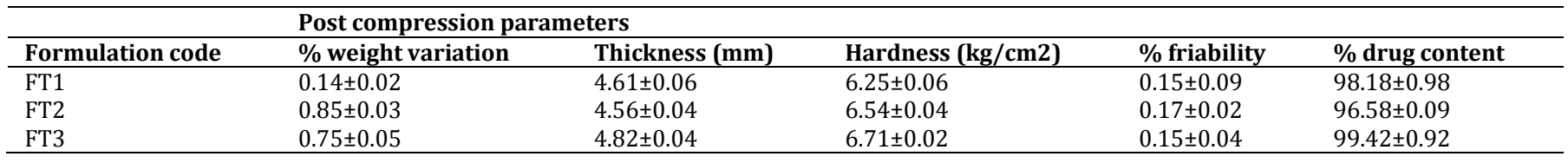

In vitro dissolution study of tablet formulations

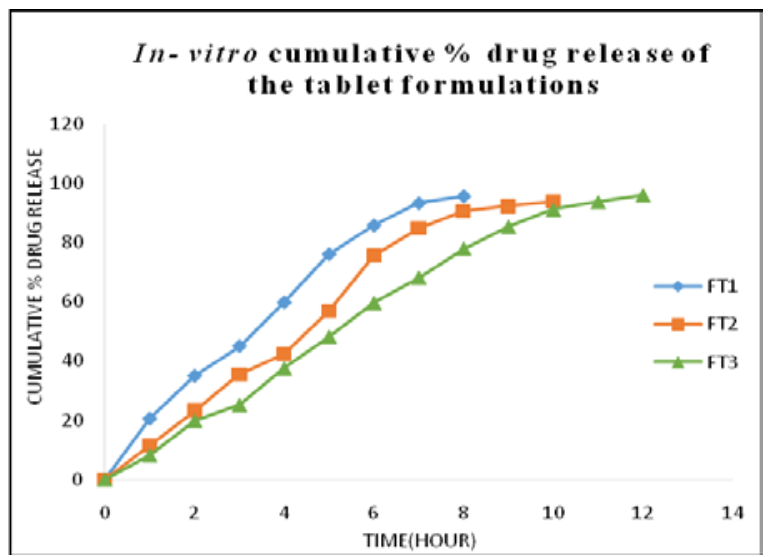

Fig. 8: In vitro cumulative $\%$ drug release of the tablet formulations

Table 9: Release kinetics data for evaluation of drug release mechanism

\begin{tabular}{|c|c|c|c|c|c|c|c|c|c|c|c|}
\hline \multirow{2}{*}{$\begin{array}{l}\text { Formulation } \\
\text { code }\end{array}$} & \multicolumn{2}{|c|}{ Zero order } & \multicolumn{2}{|c|}{ First order } & \multicolumn{2}{|l|}{ Higuchi } & \multicolumn{3}{|c|}{ Korsmeyer-peppas } & \multicolumn{2}{|c|}{ Hixson-crowell } \\
\hline & $\mathrm{k} 0$ & $\mathrm{R} 2$ & $\mathrm{k} 1$ & R2 & $\mathrm{kH}$ & R2 & kKP & $\mathrm{N}$ & R2 & $\mathrm{kHC}$ & $\mathrm{R} 2$ \\
\hline FT1 & 13.615 & 0.9546 & 0.263 & 0.9617 & 32.362 & 0.9423 & 21.418 & 0.747 & 0.9903 & 0.072 & 0.986 \\
\hline FT2 & 10.799 & 0.9604 & 0.199 & 0.9328 & 28.301 & 0.8899 & 14.842 & 0.842 & 0.9731 & 0.056 & 0.9646 \\
\hline FT3 & 8.98 & 0.9778 & 0.163 & 0.936 & 25.613 & 0.8877 & 11.844 & 0.873 & 0.9858 & 0.046 & 0.9695 \\
\hline
\end{tabular}

\section{DISCUSSION}

The solid dispersions of Ibuprofen and the sustained release tablets containing the optimised batch were prepared and evaluated for various parameters. FT-IR studies indicated that no chemical interactions took place between drug and the polymers used for the preparation of solid dispersions. Further, the FT-IR study of a physical mixture of the optimised formulation SDF9 and HPMC K100M also exhibited no drug-excipient incompatibility.

The DSC thermogram of pure ibuprofen showed a sharp endothermic peak at $81.72{ }^{\circ} \mathrm{C}$ which corresponds to its melting point The DSC thermogram of Ibuprofen-PEG 20000-Poloxmer 407 (1:3:3) solid dispersion prepared by a solvent evaporation method (SDF9) showed the endothermic peak at temperature $59.38{ }^{\circ} \mathrm{C}$ with some changes in the characteristics of the peaks. It showed that no possible interaction took place between the drug and carriers and the loss of peak sharpness indicated the conversion of a crystalline form of the drug to amorphous form.

All the solid dispersions showed a better release profile as compared to the drug and physical mixtures. Solid dispersions of ibuprofen SDF7 (1:1:1), SDF8 (1:2:2) and SDF9 (1:3:3) prepared by using a combination of PEG 20000 and Poloxamer 407 by solvent evaporation technique showed faster and better drug release as compared to other formulations and physical mixtures. Formulations SDF7 (1:1:1) and SDF8 (1:2:2) showed a good drug release of $89.24 \%$ and $93.17 \%$ respectively in $60 \mathrm{~min}$. Formulation SDF9 (1:3:3) showed a release of $95.09 \%$ in $60 \mathrm{~min}$, which was the best among all the prepared solid dispersions and thus considered as the optimised batch.
The tablet formulations containing the granules of the optimised batch of solid dispersion (SDF9) were evaluated for postcompression parameters and the results were found within the pharmacopoeial standards. The different batches were found uniform with respect to a hardness within the range of $6.25 \pm 0.06$ to $6.71 \pm 0.02 \mathrm{~kg} / \mathrm{cm}^{2}$. Another measure of a tablet's strength is friability. The percentage friability of all the formulations was found to be not more than $0.17 \%$ which is well within the limit of $<1 \%$. In weight variation test, the pharmacopoeial limit for percentage deviation for tablets of more than $250 \mathrm{mg}$ is $\pm 5 \%$ and all the formulations were found to comply with the specifications. Good uniformity in drug content was found among the formulations, and percentage of drug content was more than $90 \%$.

In vitro release rate of all designed formulations were studied up to $12 \mathrm{~h}$. Formulations FT1 and FT2 failed to sustain the release of drug upto12 h. FT1 showed $95.58 \%$ of drug release in $8 \mathrm{~h}$ while FT2 showed $93.74 \%$ of drug release in $10 \mathrm{~h}$. Formulation FT3 only succeeded to allow a sustained release of drug upto12 $\mathrm{h}$. At the end of $12 \mathrm{~h}$ the release was $96 \%$ and so it was considered as the optimised batch.

To describe the kinetics of drug release from the tablet formulations, the data obtained from in vitro drug release studies were plotted in various kinetic models that is zero order, first order, Higuchi's model, Korsmeyer-Peppas model and Hixson-Crowell cube root equation. The models with highest regression coefficient value $\left(r^{2}\right)$ were judged to be the most appropriate ones. From the release kinetics data, it was concluded that all the tablet formulations have Korsemeyer-Peppas as best fit kinetic model for drug release with $\mathrm{r}^{2}$ values of $0.9903,0.9731,0.9858$ and respectively. The release exponents (n) for the formulations were found $0.747,0.842$ and 
0.873 respectively which appears to indicate a coupling of diffusion and erosion mechanisms, so-called non-Fickian or anomalous diffusion.

\section{CONCLUSION}

The present study was aimed to increase the solubility of Ibuprofen by solid dispersion technique and to develop sustained release tablets containing solid dispersion granules of the optimised batch. Solid dispersions of Ibuprofen were prepared by using PEG 20000 and poloxamer 407 in different weight ratios by fusion method and solvent evaporation method. Drug-carrier physical mixtures were also prepared to compare the dissolution characteristics with the solid dispersions. The saturation solubility and in vitro dissolution studies revealed remarkable improvement in the solubility and dissolution from these newly formulated solid dispersions over the pure drug and physical mixtures. Formulations containing a combination of hydrophilic carriers showed better dissolution results than that of individual carriers. In every formulation, improved dissolution rate was observed with increase in polymer ratio. Solid dispersion of Ibuprofen containing PEG 20000 in combination with Poloxamer 407 in the ratio of 1:3:3 (SDF9) prepared by solvent evaporation method exhibited faster and higher drug release $(95.09 \%$ in $60 \mathrm{~min}$ ) as compared to other formulations and physical mixtures. The formulation thus selected as the optimised batch. FT-IR studies revealed no drug-carrier interaction. DSC result of the formulation indicated the transformation of crystalline ibuprofen to amorphous form which can be implicated for improved dissolution. Sustained release tablets containing the solid dispersion granules of the optimised batch were prepared by direct compression method using HPMC K100M as release retarding polymer at three different concentrations $(10 \%, 14 \%$ and $18 \% \mathrm{w} / \mathrm{w})$. FT-IR studies confirmed the drug-excipient compatibility. In vitro dissolution studies showed that with an increase in the concentration of HPMC $\mathrm{K} 100 \mathrm{M}$ in the tablets, the release rate of the drug decreases. Formulations FT1 and FT2 showed $95.58 \%$ drug release in 8 hs and $93.74 \%$ drug release in $10 \mathrm{~h}$ respectively. Formulation FT3 was found the best based on in vitro release profile of $96 \%$ drug release for $12 \mathrm{~h}$. From the release kinetics data, it was concluded that all the tablet formulations have Korsemeyer-Peppas as best fit kinetic model for drug release with $r^{2}$ values of $0.9903,0.9731$, 0.9858 and respectively. The release exponents (n) for the formulations were $0.747,0.842$ and 0.873 respectively which appears to indicate a coupling of diffusion and erosion mechanisms, so-called non-Fickian or anomalous diffusion. Thus, this study concluded that the preparation of solid dispersions using a combination of PEG 20000 and poloxamer 407 by solvent evaporation method may result in higher aqueous solubility of
Ibuprofen than that of solid dispersions containing the individual polymers. Also, formulation of sustained release tablets containing solid dispersion granules of ibuprofen, using HPMC K100M (18\% $\mathrm{w} / \mathrm{w}$ ) as release retardant polymer may be a promising approach to extend the release rate of drug from the solid dispersion for a prolonged period of $12 \mathrm{~h}$.

\section{CONFLICT OF INTERESTS}

\section{Declare none}

\section{REFERENCES}

1. Sethia S, Squillante E. Solid dispersions: revival with greater possibilities and applications in oral drug delivery. Crit Rev Ther Drug Carrier Syst 2003;20:215-47.

2. Serajuddin AT. Solid dispersion of poorly water-soluble drugs: early promises, subsequent problems, and recent breakthroughs. J Pharm Sci 1999;88:1058-66.

3. Koh PT, Chuah JN, Talekar M, Gorajana A, Garg S. Formulation development and dissolution rate enhancement of Efavirenz by solid dispersion systems. Indian J Pharm Sci 2013;75:291-301.

4. Vo CL, Park C, Lee BJ. Current trends and future perspectives of solid dispersions containing poorly water-soluble drugs. Eur J Pharm Biopharm 2013;85:799-813.

5. https://pubchem.ncbi.nlm.nih.gov/compound/3672. [Last accessed on April 18 2017]

6. Joshi HN, Tejwani RW, Davidovich M, Sahasrabudhe VP, Jemal M, Bathala MS, et al. Bioavailability enhancement of a poorly water-soluble drug by solid dispersion in polyethene glycolpolysorbate 80 mixture. Int J Pharm 2004;269:251-8.

7. Kose-Ozkan C, Savaser A, Tas C, Ozkan Y. The development and in vitro evaluation of sustained release tablet formulations of benzydamine hydrochloride and its determination. Chem Pharm Bull 2010;13:683-9.

8. Wadher KJ, Kakde RB, Umekar MJ. Formulation and evaluation of sustained-release tablets of metformin hydrochloride using hydrophilic synthetic and hydrophobic natural polymers. Indian J Pharm Sci 2011;73:208-15.

9. Bose A, Wong TW, Singh N. Formulation development and optimization of sustained release matrix tablet of Itopride $\mathrm{HCl}$ by response surface methodology and its evaluation of release kinetics. Saudi Pharm J 2013;21:207-23.

\section{How to cite this article}

- $\quad$ Abhik Kar, Abdul Baquee Ahmed. Enhancement of solubility and dissolution of ibuprofen by solid dispersion technique and formulation of sustained release tablets containing the optimised batch of solid dispersion. Int J Curr Pharm Res 2017;9(5):37-44. 